\title{
Beyond HABIT: The Role Of Sunk Costs on DeVELOPING AUTOMATIC IS USE BEHAVIORS
}

\author{
Jeffrey A. Clements \\ Weber State University \\ jeffreyallenclements@gmail.com
}

\begin{abstract}
Habitual routine behaviors and their subsequent conditioned response behaviors are two very powerful determinants of future human behavior. This study conceptualizes the habits or routines that people engage in with technology as being distinct and apart from automatic IS use behaviors. Automatic IS use behaviors - of which people are often unaware of the behavior until reflecting backward upon it - are hypothesized to be a result of a person's interaction with certain technology features which act as stimulus and reward mechanisms. Additionally, the roles of habit and a person's perception of sunk costs are hypothesized to play an important role in the development of automatic IS use behaviors. An international study of 177 individuals using a wide range of technologies provides support for the proposed relationships. The findings of the study, the limitations, and directions for future research are also discussed.
\end{abstract}

\section{Keywords}

Human factors, design, habit, automatic IS use, technology engagement

\section{INTRODUCTION}

To stay competitive in the marketplace and to capture high use technology users companies strive to create products or services that are sticky. They want customers or users that visit their website or use their product or service to visit often and stay for a long time during each visit. This is especially true for companies doing business directly with consumers through voluntary-use information systems and technologies. Voluntary-use information systems and technologies are defined as applications, systems, programs or technologies that people voluntarily interact with outside of their employment. To be sustainable, voluntary-use information systems must have this stickiness factor (i.e., platforms such as Apple's Iphone or Google's Android, or applications such as Facebook, Pinterest, Twitter or Angry Birds) in order to rely on habitual technology users for their success. Industry estimates for consulting firms that help companies develop aspects which increase stickiness foresee revenues totaling $\$ 1.6$ billion by 2015 (MacMillan, 2011).

Understanding why people choose to adopt, choose to use, and choose to continue to use a specific information system (IS) has been a topic extensively researched in the MIS field (e.g., Bhattacherjee, 2001; Davis, Bagozzi \&Warshaw, 1989; Tiwana \& Bush, 2005; Venkatesh, Morris, Davis \& Davis, 2003). Extant literature provides numerous models and frameworks which inform our understanding of phenomena related to various stages of intentional IS use behaviors (Thompson, Higgins \& Howell, 1991; Venkatesh \& Davis, 1996; Al-Natour \& Benbasat, 2009). The common thread throughout this research is that the focus has primarily been on (1) the intentional choices and behaviors of individuals directed towards an information system or technology in a (2) mandatory context or work-related setting. Very little research has begun to explore the flipside of these assumptions and look at the (1) non-intentional interactions individuals have with information systems and technologies in (2) voluntary contexts and non 
work-related environments. To address these gaps this study focuses on voluntary-use information systems.

This study conceptualizes the purposeful interactions and routines that people engage in with technology as being distinct and apart from automatic IS use - use of an IS where the user is unaware of the use until he or she reflects backward upon it. Despite the powerful practical implications for business, automatic IS use is an understudied concept in the IS continuance literature. Automatic IS use is the spontaneous interaction with an information system or technology, triggered by sensory cues and preceding actions. In this study's conceptual development of an automatic IS use model, I employ Simon's (1950) framework of the mechanisms of behavioral initiation and mechanisms of behavioral persistence to explain both individual mechanisms and the technology-enabled mechanisms of initiation which lead to behavioral persistence. The purpose of this research is to explore how the behavioral initiation mechanisms of a person's habits and reward responsiveness along with the cues and rewards provided by the technology can increase the person's perceptions of sunk costs. In turn, I explore how increased perceptions of sunk cost (e.g., time spent previously with the technology, the effort spent learning the technology, effort spent customizing the experience, money spent on the technology) can lead to an increase in automatic IS use. Thus, the primary research question guiding this study is how do automatic IS use behaviors develop? Next, I will discuss the study's theoretical development, research model and hypotheses, methodology and results, and finally the findings and limitations.

\section{THEORETICAL DEVELOPMENT}

Figure 1 represents this study's conceptual model. The individual behavioral initiation mechanisms and the technology-enabled behavioral initiation mechanisms lead to psychological behavioral persistence mechanisms. This in turn drives automatic behavioral engagement.

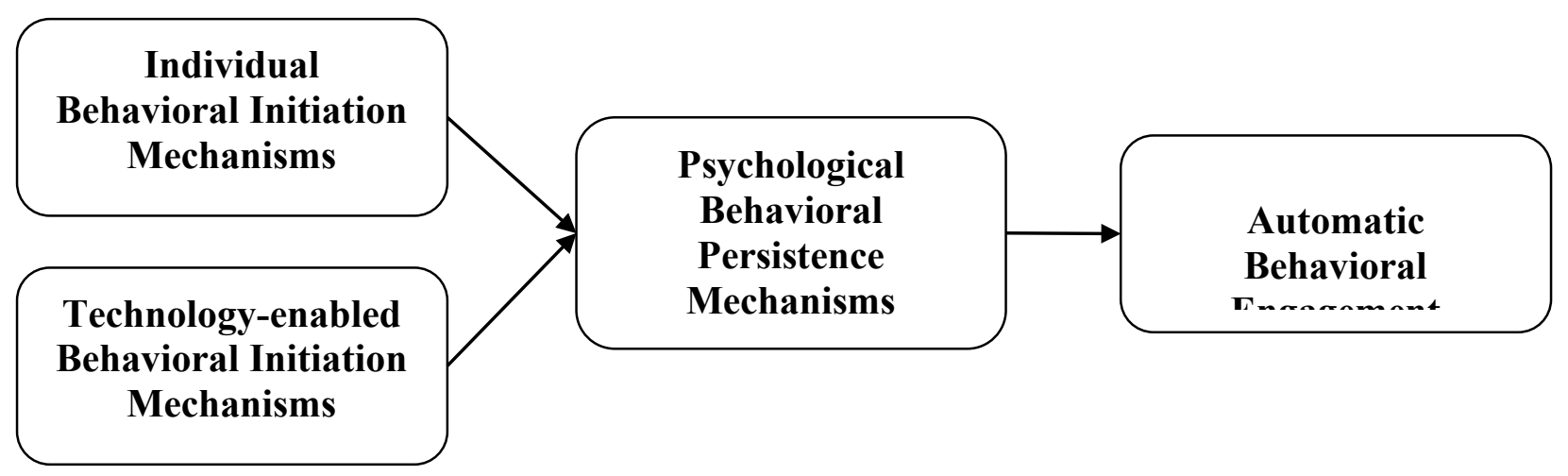

Figure 1. Conceptual Model of Automatic Behavioral Engagement

The Mechanisms of Behavioral Initiation and Behavioral Persistence

Simon's (1950) seminal work on administrative behavior provides a general pattern of behavior. To briefly summarize, there are two principle sets of mechanisms that distinguish behavior. First, there are those that initiate and stimulate a behavior to commence in a particular fashion. Simon calls these initiatory mechanisms the mechanisms of behavioral initiation. Second, there are psychological mechanisms, internal to the individual, which cause an initiated behavior to persist once it has been initiated. He calls these the mechanisms of behavioral persistence. Combined these serve to free the individual from the cognitive burdens associated with intentional action and serve to automatically engage behaviors.

According to Simon, the mechanisms of behavioral initiation are largely external to the individual. These initiatory mechanisms also imply that the individual is sensitive to particular stimuli associated with the behavior (Simon, 1950, pp. 94). These concepts are captured in the current study's conceptualization of (1) the features of the technology which act to initiate behavior such as the embedded cuing mechanisms 
of a technology, the embedded reward mechanisms of a technology and the facilitating conditions of a technology, and (2) the individual's sensitivity towards receiving a rewarding stimulus.

In contrast, the mechanisms of behavioral persistence are largely psychological and can be found internal to the individual. These mechanisms serve to cause the behavior to continue its course once the behavior has been initiated in a particular direction. As Simon (1950) notes, "One important reason for behaviorpersistence is that activity very often results in sunk costs of one sort or another that make persistence in the same direction advantageous" (pp. 95). This concept is captured in the current study's conceptualization of the individual's perceptions of sunk costs. Perceptions of sunk costs are defined as an individual's perception of a previous investment in money, effort, or time (Arkes and Blumer, 1985). As mechanisms of behavioral persistence become activated in the individual, the activity persists because of the individual's perception of sunk costs accrued as a result of engaging in this activity. This concept of persistent engagement of an activity has been captured in this study's conceptualization of automatic IS use behaviors. Next, I will discuss the research model and hypothesis development.

Research Model

The research model contains exogenous factors representing mechanisms of behavioral initiation, and endogenous factors representing the mechanisms of behavioral persistence with the outcome of automatic behavioral engagement. Briefly explained, the individual behavioral initiation mechanisms-which represent my application of Simon's concept of the individual's sensitivity to particular stimuli - consist of the individual's current habits and the individual's reward responsiveness. In addition, the technologyenabled behavioral initiation mechanisms - which represent my application of Simon's concept of mechanisms external to the individual - consist of the technology-enabled cuing mechanisms embedded within the system, the technology-enabled reward mechanisms embedded within the system, and the facilitating conditions of the system. These factors contribute to automatic behavioral engagement-i.e., automatic IS use - through the psychological behavioral persistence mechanism of perceptions of sunk costs.

Next, I will discuss each of these concepts as I review relevant literature informing the research model and develop the hypotheses. Figure 2 presents the research model and Table 1 summarizes the constructs and their definitions. 


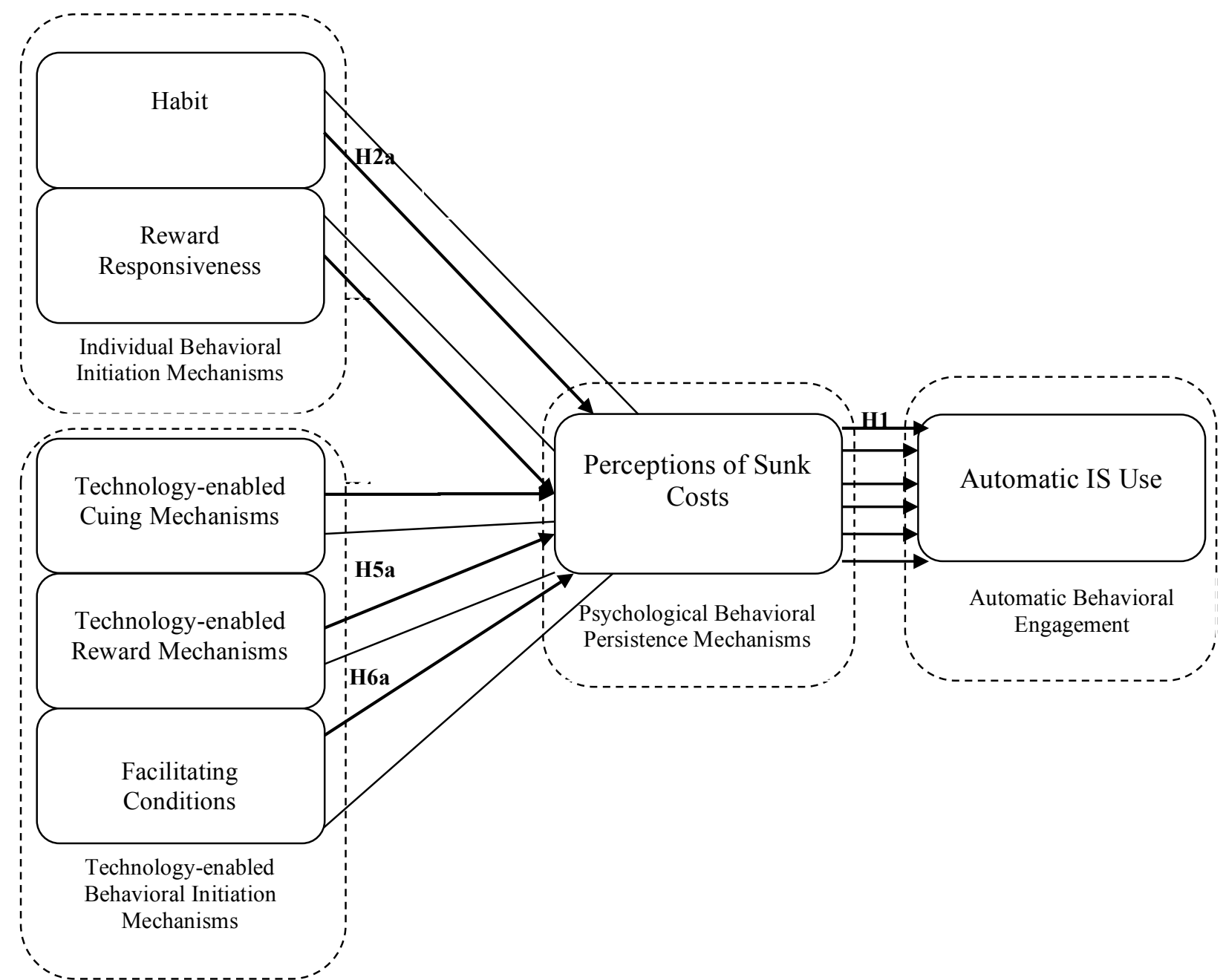

Figure 2. Research Model

\begin{tabular}{|c|l|c|}
\hline Construct & \multicolumn{1}{|c|}{ Definition } & Informing Source \\
\hline Automatic IS Use & $\begin{array}{l}\text { Spontaneous interaction with an information system or } \\
\text { technology, triggered by sensory cues and preceding } \\
\text { actions-the cuing of which proceeds without recourse to } \\
\text { goal-related constructs of volition and will }\end{array}$ & $\begin{array}{c}\text { Neal, 2007, de Guinea and } \\
\text { Markus, 2009) }\end{array}$ \\
\hline $\begin{array}{c}\text { Perceptions of Sunk } \\
\text { Costs }\end{array}$ & $\begin{array}{l}\text { An individuals perception of a previous investment in } \\
\text { money, effort, or time }\end{array}$ & $\begin{array}{c}\text { (Arkes and Blumer, 1985, } \\
\text { Clements and Bush, 2011) }\end{array}$ \\
\hline Habit & $\begin{array}{l}\text { The extent to which people tend to perform behaviors (use } \\
\text { IS) automatically because of learning }\end{array}$ & (Limayem et al., 2007) \\
\hline $\begin{array}{c}\text { Reward } \\
\text { Responsiveness }\end{array}$ & $\begin{array}{l}\text { An individual's sensitivity to rewards which manifests as a } \\
\text { strong pursuit of appetitive goals, a tendency to seek out } \\
\text { new potentially rewarding experiences, or a tendency to act }\end{array}$ & (Carver \& White, 1994) \\
\hline
\end{tabular}




\begin{tabular}{|c|l|c|}
\hline & quickly in pursuit of desired goals & \\
\hline $\begin{array}{c}\text { Technology-enabled } \\
\text { Cuing Mechanisms }\end{array}$ & $\begin{array}{l}\text { Features or functionalities embedded within an information } \\
\text { system or technology which provide behavioral cues, } \\
\text { stimuli, or triggers }\end{array}$ & $\begin{array}{c}\text { (Hull, 1943; Neal et al., } \\
\text { 2006, Wood and Neal, 2007) }\end{array}$ \\
\hline $\begin{array}{c}\text { Technology-enabled } \\
\text { Reward Mechanisms }\end{array}$ & $\begin{array}{l}\text { Features or functionalities embedded within an information } \\
\text { system or technology which provide valuable or rewarding } \\
\text { feedback stimuli }\end{array}$ & $\begin{array}{c}\text { (Hull, 1943, Dahlstrand and } \\
\text { Biel, 1997, Wood et al., } \\
\text { 2002) }\end{array}$ \\
\hline $\begin{array}{c}\text { Facilitating } \\
\text { Conditions }\end{array}$ & $\begin{array}{l}\text { An individual's perception of factors present in either the } \\
\text { technology or the environment, which enable and facilitate } \\
\text { ubiquitous interaction with the technology }\end{array}$ & $\begin{array}{c}\text { (Triandis, 1977, Limayem } \\
\text { and Hirt, 2003, Venkatesh et } \\
\text { al., 2003) }\end{array}$ \\
\hline
\end{tabular}

Table 1. Constructs and Definitions

Automatic Behavioral Engagement: Automatic IS Use

Building upon the work of Wood and Neal (2007) and the classic definition of automatic behavior by William James (1890), automatic IS use is defined as the spontaneous interaction with an information system or technology, triggered by sensory cues and preceding actions - the cuing of which proceeds without recourse to goal-related constructs of volition and will. In this sense automatic IS use is nonintentional, non-voluntary, and occurs without the mental engagement of determination. It is a contextresponse association which is not mediated by goals (Wood and Neal, 2007). This type of technology use is not driven by a person's conscious decision to continue to use an IS, and not guided by purposeful intentions, volition or will. One example of this can be seen in the high use Blackberry user whose email checking has become so automatic that a simple buzz of the phone or mere sight of his phone instigates the automatic behavioral sequence of taking out the phone to check the message. This automatic behavioral response is distinguished from the habit of checking your email on your phone when you get to work in the morning. This distinction between intentional habit and the non-volitional automatic behavioral sequencing of automatic IS use is discussed next.

\section{Distinguishing Automatic IS Use}

Research on the automaticity of habits and goals by Wood and Neal (2007) demonstrates that once habits are formed automatic behavioral responses (e.g., automatic IS use) can be primed and subsequently performed without mediation of a goal to achieve a particular outcome or even a goal to respond (i.e., a behavioral intention). This automatic behavioral action is non-intentional and is performed without the individual being aware of the action. It is often only after the behavior has been cued and performed that the individual can reflectively look back and can recognize his actions. As Simon notes, "the automatically primed responses cannot be thought of as a purely passive element in behavior as the mere presence of the stimulus tends to release the behavior without conscious thought" (Simon, 1950 pp. 89).

Very complex non-intentional behavioral sequences can be accomplished in this automatic fashion. A common example of this can be seen in the person who intends to drive to the beach on a Saturday morning but ends up in his place of business instead. The simple stimulus of an off-ramp or a glance at the dashboard clock or even the act of driving triggers a series of behavioral sequences that are automatically performed outside of the person's intentions or even awareness. This current study conceptualizes the dependent variable automatic IS use, in a similar fashion.

Psychological Behavioral Persistence Mechanisms: Perceptions of Sunk Costs 
Behavioral persistence mechanisms are those psychological processes which cause a behavior to persist once the behavior has been initiated. Behavioral persistence mechanisms provide mechanisms through which automatic IS use behaviors can be sustained. Sunk cost theory provides a lens to understand the effect of irretrievable costs on a user's behavior. The sunk cost effect is manifested in a greater tendency to continue an endeavor once an investment in money, effort, or time has been made (Arkes and Blumer, 1985). The main argument presented in this theory is that the prior investment which is motivating the present decision to continue does so despite the fact that it objectively should not influence the decision. Rationally we should not consider the previously expended money, time, or effort we have put into the use of a technology when we are considering whether or not to continue using the technology. However our perceptions of past expenditures with a technology have been shown to influence the future continued use of the technology (Al-Natour and Benbasat, 2009). Furthermore as Simon noted, perceptions of sunk costs drive behavior non-rationally.

Our expended time and efforts (e.g., finding and building our friends on Facebook, our followers on Twitter, or our playlists on Spotify) should not influence our continued use. However, sunk cost theory suggests that this is not always the case. Tiwana and Bush (2005) developed an expertise-sharing network continuance model which demonstrates how certain factors that emerge through irretrievable investments by individual users after initial adoption influence continuance. Our perceptions of the investment (actual or implied) we have made in conjunction with using a particular technology will likely influence our automatic use of the technology once usage behaviors have been engaged. These perceptions demonstrate that we feel we have somehow contributed time, energy, resources, or efforts into the technology we are using. Because of our perceptions of this investment, we become compelled to continue using whatever we have sunk this investment into (Staw and Hoang, 1995; Tiwana and Bush, 2005).

Sunk costs represent an important behavioral persistence mechanism (Simon, 1950). Once the behavior has been triggered, persistence mechanisms strengthen and drive the behavior autonomously. In line with Simon's (1950) framing, we believe that a user's perceptions of their irretrievable costs such as time and effort spent with the technology will be positively associated with their automatic use of the technology. Therefore

H1 - An individual's perceptions of sunk costs will be positively associated with automatic IS use.

\section{Behavioral Initiation Mechanisms}

The mechanisms of behavioral initiation serve the purpose of initiating a behavior in a particular direction. First, there are mechanisms which are largely external to the individual which include context and stimuli to initiate action. In this study the features of a technology which act to initiate behaviorssuch as the embedded cuing mechanisms of a technology, the embedded reward mechanisms of a technology and the facilitating conditions of a technology - can be considered mechanisms of behavioral initiation. Second, there are internal mechanisms which initiate action which account for an "individual's sensitivity to particular stimuli" (Simon, 1950, pp. 94). In this study an individual's current technology habits and an individual's sensitivity towards receiving a rewarding stimulus represent mechanisms of behavioral initiation. Next, I will discuss the internal and individual mechanisms (e.g., habit and reward responsiveness) followed by the external and technology-enabled mechanisms (e.g., technology-enabled cuing, technology-enabled reward, and facilitating conditions).

Habit

Most habits that are studied by social psychologists are intentional (Verplanken \& Orbell, 2003). The importance of habits in determining future behavior has long been equated to behavioral frequency (Triandis, 1977). Though habits do develop though satisfactory repetition of behaviors in stable contexts, behavioral frequency alone does not necessarily equate to habit formation (Wood et. al., 2002). Research viewing habit apart from frequency has provided insight into viewing habit as a mental construct (Verplanken, 2006), one in which the role of habit cannot be properly investigated without independent measures for habit (Ajzen \& Fishbein, 2005). IS research has viewed habit as the extent to which people 
tend to perform behaviors (use IS) automatically because of previous learning (Limayem et al., 2007). Habits in this sense can be defined as learned sequences of acts that are functional in obtaining certain goals or end states (Verplanken \& Aarts, 1999). Thus, habits as behavioral initiators lead to an automaticity of behavior that is performed without awareness, is difficult to control, and is mentally efficient (Verplanken \& Orbell, 2003). Habits do so as to permit the conservation of mental effort through withdrawal from the area of conscious thought (Simon, 1950). A strong technology habit would indicate a high level of previous learning and thus an increased perception of the time and effort spent learning the technology. Therefore,

$\mathrm{H} 2 \mathrm{a}$ - Habit will be positively associated with the perceptions of sunk costs

Habit as an initiator will be followed by and sustained by behavioral persistence mechanisms resulting in automaticity of behavioral engagement. Following Simon (1950), I expect habit to increase automatic IS use because it increases an individual's perceptions of sunk costs. Thus,

$\mathrm{H} 2 \mathrm{~b}$ - The effect of habit on automatic IS use will be mediated by perceptions of sunk costs

Reward Responsiveness

In addition to certain external features or functionalities that are present in information systems and technologies which serve as behavioral initiation mechanisms, there are key behavioral initiation factors which are internal to and specific to the individual using the technology. These individual differences in both the technology and the facets of the individual promote the automaticity of behavior provde a way to account for differences in why certain people who repeatedly performing the same task with the same goal orientation vary on whether or not they engage in non-volitional, spontaneous and automatic behaviors. Gray's (1990) theory of brain functions and behavior provides a solid theoretical foundation to understand these differences in terms of an individual's sensitivity toward receiving rewards.

Gray's (1990) theory explains that individual's differ in their sensitivity to cues indicating reward (i.e., positive feedback), non-punishment, and escape from punishment (i.e., negative feedback). Individuals that are highly sensitive to rewards engage in or increase in goal attainment processes, and feel more joy, hope and happiness. This sensitivity is represented in this study as reward responsiveness. Reward responsiveness refers to an individual's sensitivity to rewards and is likely to manifest as strong pursuit of appetitive goals, or as a tendency to seek out new potentially rewarding experiences, or a tendency to act quickly in pursuit of desired goals (Carver \& White, 1994.) Thus reward responsiveness operates as a behavioral initiation mechanism. Therefore highly reward responsive individuals using a technology will have increased evaluations of their previous time or effort spent with a technology. Therefore,

$\mathrm{H} 3 \mathrm{a}-$ Reward responsiveness will be positively associated with perceptions of sunk costs.

Following the Simon's framing, reward responsiveness as a behavior initiator will be followed by and sustained by behavioral persistence mechanisms resulting in automaticity of behavioral engagement. Thus as the individual becomes more sensitive to the rewards provided by a technology their automatic technology use will be greater. This is due to the increased evaluation of their previous time or effort spent using the technology which acts as a mechanism of behavioral persistence. Therefore,

$\mathrm{H} 3 \mathrm{~b}$ - The effect of reward responsiveness on automatic IS use will be mediated by perceptions of sunk costs.

Technology-enabled Cuing Mechanisms

Most classic behavioral theories point to the importance of an external stimulus to initiate action. Hull's Stimulus Response Theory (1943) and other theories of classical conditioning suggest that all behaviors must first be primed or cued before the behavior can be engaged. This study's assumption is that a system or technology can provide the necessary external priming stimuli in the form of technology-enabled cuing mechanisms. Technology-enabled cuing mechanisms are defined as the features or functionalities embedded within an information system or technology which provide behavioral cues, stimuli, and/or 
triggers. These technology features serve as external behavioral initiation mechanisms which set behaviors into motion (Simon, 1950).

These embedded cuing mechanisms can present themselves in a number of forms. Take for example today's smart phone device. Consider the variety of indicator lights of varying colors, and flashes of varying intensity. Consider the innumerable combination of vibration sequences, visual alerts, symbols, or messages. Consider the variety of audible sounds, beeps, tones and rings. All serve the purpose of signaling to their human operator, "Hey...I have something for you... Look at me... Listen to me... Pick me up... Interact with me." This has important implications for the design of a technology as technologyenabled cuing mechanisms can be purposefully incorporated into a system to act as mechanisms of behavioral initiation. This point is reflected in recent calls for information systems research that is design science oriented (Havner, March, Park and Ram, 2004). Once the behavior is primed and initiated there are psychological processes which provide guidance and persistence for the action. Thus, people interacting with those systems or technologies will have higher evaluations of their past use (i.e., perceptions of sunk costs). Therefore

$\mathrm{H} 4 \mathrm{a}$ - Technology-enabled cuing mechanisms will be positively associated with perceptions of sunk costs.

It follows that as perceptions of sunk costs operate as a psychological behavioral persistence mechanism, these individuals will begin to develop automatized context-response associations in the form of automatic IS use. As such technologies with high levels of cuing mechanisms will engender high levels of automatic IS use because of the increase in perceptions of sunk cost. Therefore,

$\mathrm{H} 4 \mathrm{~b}$ - The effect of technology-enabled cuing mechanisms on automatic IS use will be mediated by perceptions of sunk costs.

Technology-Enabled Reward Mechanisms

One central tenet in the development of strong automatic response associations (i.e., automatic IS use) is the strength of the relationship - the value association-between the behavior and the ensuing reinforcement or reward. Classic behavioral theories, such as Hull's Stimulus Response Theory (1943), demonstrate that the strength of a behavior is reflected in the extent to which the behavior has been reinforced in the past. This reward or reinforcement can be either negative or positive. Positive reinforcement occurs when a cued behavior is followed by a positivity valued rewarding stimulus, thereby increasing the frequency of that behavior. Negative reinforcement occurs when a triggered behavior is followed by the removal of an aversive or negatively valued stimulus, also increasing the frequency of behavior. Research in the area of habit formation has shown that feedback in the form of positive or negative reinforcement has a compounding effect on the strength and frequency of habitual behaviors (Dahlstrand and Biel, 1997). In similar fashion the immediacy of the feedback can further strengthen the development of a habit.

More recent research building on incentive conditioning suggests that when behavioral cues are associated with a rewarded response, the value associated with the reward becomes ingrained and conditioned into the cues themselves. (Neal et al., 2006) Thus as the behavior is subsequently performed the cues themselves begin to carry value enough to motivate action. The behavior is driven because the past reward conditioning has established the necessary cognitive context-response associations, and henceforth the context becomes embedded with the motivational force for responding (Wood et al., 2007).

An information system or technology can serve as the context for individuals to perform a variety of behaviors. To illustrate, consider the context of an individual and their smartphone. Research on smartphone use shows that automatic checking behaviors emerge and are reinforced by the quickly accessible informational rewards provided by the smartphone (Oulasvirta et al., 2012). Thus it stands to reason that if an information system or technology can provide the mechanisms of behavioral initiation 
(e.g., technology-enabled reward mechanisms), then people interacting with those systems or technologies will have increased evaluations associated with their past time and effort spent with the technology (i.e., perceptions of sunk costs). Therefore,

$\mathrm{H} 5 \mathrm{a}$ - Technology-enabled reward mechanisms will be positively associated with perceptions of sunk costs.

As a individual's perceptions of sunk costs acts as a psychological behavioral persistence mechanism, these individuals will begin to develop automatized context-response associations in the form of automatic IS use. Thus technologies providing high levels of rewards will engender high levels of automatic use because of the individual's increased perception of sunk costs. Therefore

$\mathrm{H} 5 \mathrm{~b}$ - The effect of technology-enabled reward mechanisms on automatic IS use will be mediated by perceptions of sunk costs.

Facilitating Conditions

Once an individual's interaction with a technology becomes sufficiently non-intentional and nonvolitional, the mere presence of the technology is stimulus enough to trigger automatic use behaviors whether we realize it or not. This association may be the reason why facilitating conditions have failed to predict behavioral intention while still directly influencing actual use (Venkatesh et al., 2003). This coincides with research that has used facilitating conditions as an antecedent to IS use (Thompson, Higgins and Howell, 1991). In support of this Venkatesh et al. (2003) found facilitating conditions bypassed behavioral intent and had a direct effect on actual use when developing the UTAUT model, meaning that having strong facilitating conditions (i.e., the presence of technology) directly contributes to technology use. One example can be seen in individuals who habitually use instant messaging in social contexts. Given the necessary facilitating conditions, these individuals also have higher uses of instant messaging in in the workplace (Ip and Ho, 2015).

Facilitating conditions have been viewed as objective factors in the environment that observers agree make an act easy to do (Triandis, 1977), including the provision of computer support (Venkatesh et al., 2003). Current conceptualizations of facilitating conditions deal with components of how much understanding a person has on the use of a technology, how easy the access is to the technology and how inexpensive the access is to the technology. These measures have primarily been employed with an individual's mandatory IS use, or intentional IS use in a work-related environment. In contrast, this study focuses on non-intentional automatic IS use of voluntary-use information systems in non work-related settings. Therefore, I define facilitating conditions as an individual's perception of factors present in either the technology or the environment which enable and facilitate ubiquitous interaction with the technology.

Facilitating features of voluntary-use information systems or technologies include cross platform availability, cross system compatibility and global accessibility. In essence these features serve as behavioral initiation mechanisms indicating the technology is ubiquitously available, compatible and accessible. Technologies that are highly available (e.g., increased facilitating conditions) initiate behavioral engagement. Technologies that are unavailable prohibit behavioral engagement. As such, if a person perceives that an information system has features which enable universal accessibility, then his/her usage behavior is thus readily primed and initiated. It follows that he/she will have higher evaluative associations of his/her past time or effort in using the technology (i.e., perceptions of sunk costs). Therefore,

H6a - Facilitating conditions will be positively associated with perceptions of sunk costs

As perceptions of sunk costs operate as a psychological behavioral persistence mechanism, technologies with high levels of facilitating conditions will see higher levels of automatic IS use. Following Simon's framing I suggest that the technology conditions which serve as initiatory mechanisms are related to the 
automatic use of the technology because of the user's perception of the sunk costs which are causing the behavior to persist. This leads to the final hypothesis.

$\mathrm{H} 6 \mathrm{~b}$ - The effect of facilitating conditions on automatic IS use will be mediated by perceptions of sunk costs

\section{METHODOLOGY}

Two samples were obtained in an effort to explore and refine the constructs in the model of automatic IS use behaviors. First, a convenience sample of 30 undergraduate and graduate students at a large southern university were recruited to complete an initial pilot test of the full survey instrument. The makeup of the group was 15 males and 15 females with an average age grouping variable of 4.4 (age category 4 consists of 26-34 year olds) completed the survey.

The second sample respondents, consisting of 140 English speaking certified workers for Amazon.com's Mechanical Turk program, were paid to complete the second pilot survey. This international sample consisted of workers from the following countries: Austrailia, Bangladesh, Canada, Germany, Greece, India, Iraq, Italy, Macedonia, Romania, Servia, Slovenia, Spain, Thailand, Tunisia, and the United States. The highest represented nationalities were from India (46\%) and the United States (37\%). Analysis of the sample showed that one worker from India had submitted two surveys, one completed and one incomplete, thus the incomplete survey was discarded to leave a total of 139 completed surveys. The average respondent age grouping variable was 4.2 (age category 4 consists of 26-34 year olds).

A between group T-Test for the two samples indicated that there was no significant difference between groups and thus the data was pooled. The makeup of the total pooled sample of 176 respondents was of $46 \%$ female and $54 \%$ male with an average age grouping of 4.2 (age group $4=26-34$ year olds, age group $5=35-45$ year olds), average education grouping of 4.6 (education group $4=$ an Associate's degree, education group $5=$ a Bachelor's degree) with an average GPA grouping of 5.2 (GPA group $4=2.5$ 2.99, GPA group 5 = 3.0-3.49).

\section{Measure Development}

Previously validated measures were used where possible for the constructs of interest and the control constructs. These include: Reward Responsiveness (Carver \& White, 1994), Impulsiveness (Whiteside and Lynam, 2001), Facilitating Conditions (Venkatesh et al., 2003; Limayem \& Hirt, 2003), Frequency of Use (Bagozzi \& Warshaw, 1990, Limayem et al., 2007), Habit (Limayem \& Hirt, 2003; Limayem et al., 2007), Satisfaction (Bhattacherjee, 2001), Perceived Ease of Use (Moore \& Benbasat, 1991), Perceived Usefulness (Limayem et al., 2007), Complexity (Venkatesh et al., 2003), Playfulness (Venkatesh, 2000), Intrinsic Motivation (Venkatesh et al., 2003), Affect Toward Use (Thompson et al., 1991), Perceived Voluntariness of Use (Moore \& Benbasat, 1991), and IS Continuance Intention (Bhattacherjee, 2001). Newly developed items were used for the following constructs: Automatic IS Use, Technology-enabled Cuing Mechanisms, Technology-enabled Reward Mechanisms, and Perceptions of Sunk Costs. Additionally, 3 new items were written and added to the previously validated measures of facilitating conditions, which captured this study's updated conceptualization of that variable.

Measures for the new constructs were developed through an iterative process where the researchers initially specified the construct domain for each variable. Specifying the domain of each variable was guided by the relevant research and theories of each respective construct. A minimum of 10 (maximum of 20) items per construct were generated and revised multiple times through the guidance and consultation of area experts. Items were then pilot tested using the first sample $(\mathrm{N}=30)$ and subsequently tested on the data sample $(\mathrm{N}=147)$. Analysis on the data was done after the pilot to insure reliability and validity of each construct (Moore \& Benbasat, 1991). Items that performed poorly were removed and measures were checked for convergent and discriminant validity. The finalized constructs used in the research model were operationalized as described below. A full table of the measures can be found in the Appendix.

Measures 
Automatic IS Use (AutoUse) - As one of the primary goals of this study is to successfully explore the domain of the automaticity of behaviors associated with the use of information systems and technology, a self-report instrument to measure automatic IS use was developed. Aspects of automaticity guided the development of the instrument such as: lack of awareness, lack of planning, feeling compelled, finding oneself mid behavioral sequence, lack of intent. To tap into these domain aspects, 15 items were created for the initial survey measure.

Final operationalization of Automatic IS Use used five seven-point Likert type measures with scores from 1 (indicating low levels of automatic IS use) to 7 (indicating high levels of automatic IS use). It is necessary that this measure of automatic IS use does not measure habit, though habit itself is a necessary precursor for the development of non-intentional automatic use behaviors. As such, factor analysis should show sufficient discriminant validity between IS habit and automatic IS use.

Habit (Hab) was operationalized using three seven-point Likert type measures with scores ranging from 1 (indicating low levels of technology habits) to 7 (indicating high levels of technology habits). Existing scales from Limayem et al., 2007 and Limayem and Hirt, 2003 were adapted to fit the context of the study. Factor analysis reduced the total retained items for operationalization and hypothesis testing to three.

Technology-enabled Cuing Mechanisms (Urgen) was operationalized using three seven-point Likert type measures with scores from 1 (indicating low levels of cuing provided by the technology) to 7 (indicating high levels of cuing provided by the technology). To capture the content domain of this newly formed construct five items were originally written. However, factor analysis revealed two items performed poorly and were not retained in the final operationalization of the construct.

Technology-enabled Reward Mechanisms (Rewar) was operationalized using three seven-point Likert type measures with scores from 1 (indicating low levels of reward stimulus provided by the technology) to 7 (indicating high levels of reward stimulus provided by the technology). Five new measures reflecting the newly developed construct were written, however factor analysis revealed two items performed poorly and were not retained in the final operationalization of the construct.

Facilitating Conditions (Facil) was operationalized using three seven-point Likert type measures with scores from 1 (indicating the technology offered low amounts of cross platform availability, cross platform-compatibility, and global accessibility) to 7 (indicating the technology offered high amounts of cross platform availability, cross platform-compatibility, and global accessibility). The original measures proposed by Venkatesh et al. (2003) were collected, however, as they did not reflect the current conceptualization of the construct the newly written measures were retained.

Reward Responsiveness (Depend) was operationalized as a reflective second order construct consisting of three distinct underlying factors. Each of the three underlying factors consisted of three seven-point Likert type measures with scores from 1 (indicating a low level of agreement with the BAS scale item) to 7 (indicating a high level of agreement with the BAS scale item). This operationalization reflects that of Carver and White (1994), the scale's authors.

Control Variables - Recent research has proposed several important antecedents of IS habits such as satisfaction, importance, prior IT use, and task complexity (Lankton, Wilson and Mao, 2010; Limayem et al., 2007). To further demonstrate discriminant validity of Automatic IS Use and IS Habit, the proposed antecedents of IS habit were used as controls for the model. These controls (satisfaction, prior IT use, task complexity) should prove predictive of Habit, but not of Automatic IS Use.

All items for the control variables were from existing previously validated scales. As such the items were computed to form the respective scales for the constructs. Before computing scales all necessary data transformation steps were performed. In total, scales were created for the following latent and observed control variables: Impulsiveness, Frequency of Use (Freq), Perceived Ease of Use (EaseofUse), Confirmation, Perceived Usefulness (Usefulness), Continuance Intention (ContinueIntent), Complexity, 
Satisfaction, Playfulness, Intrinsic Motivation (IntMotiv), Affect Towards Use (Affect), Perceived Voluntariness of Use, GPA, Age and Gender. The scales were then checked for violations of the assumptions of normality and linearity. Examination of histograms, scatter plots, P P-Plots, and skewness statistics gave no indication of a violation of the assumptions of normality.

Factor Analysis

Before factor analysis could be performed a data transformation step was performed to sensibly scale the reverse coded items. The next step performed was an exploratory factor analysis of the items for our variables in model. This was done as many new items had been created for the model. The EFA was performed to both assess the loadings of the items on their intended construct and to reduce redundancy resulting in a total number of items necessary to ensure sufficient internal validity and reliability as well as discriminant validity. The data reduction technique used was a principle components analysis with pairwise deletion (to deal with any missing data), and with a varimax rotation (for interpretation amelioration). Factors were extracted based on Kaiser's (1970) criterion of retaining items with eigenvalues greater than 1.0.

The initial analysis showed 18 factors based on the eigenvalue greater than one criterion. The total variance explained by the factors was a $75.14 \%$. By examining the rotated solution, items were next systematically removed one at a time for low loadings and cross loadings. Following item elimination the final rotated factor pattern showed all individual items had loaded on their intended factor and there were at least three items remaining in every scale. Some of the newly created scales (i.e., Technology-enabled cuing mechanisms labeled as "Urgen1", and Facilitating Conditions labeled as "Facil8") have lower than ideal loadings (.48, and .54) but given they are conceptually new measures they will be retained for further analysis. The results from the factor analysis are reported below in Table 2. 
AutoUse=Automatic IS Use; Sunk=Perceptions of Sunk Costs; Hab=Habit; Depend=Reward Responsiveness; Rewar=Technology-enabled Reward Mechanisms; Facil=Facilitating Conditions, Urgen=Technology-enabled Cuing Mechanisms

\begin{tabular}{|c|c|c|c|c|c|c|c|c|c|}
\hline \multicolumn{10}{|c|}{ Rotated Component Matrix ${ }^{\mathrm{a}}$} \\
\hline & \multicolumn{9}{|c|}{ Component } \\
\hline & 1 & 2 & 3 & 4 & 5 & 6 & 7 & 8 & 9 \\
\hline AutoUse9 & .829 & .149 & .079 & -.025 & .077 & .070 & .136 & .042 & -.083 \\
\hline AutoUse12 & .809 & .092 & .069 & .090 & .068 & -.070 & -.052 & .029 & .209 \\
\hline AutoUse8 & .801 & .207 & .153 & .088 & .108 & .144 & .103 & .102 & .016 \\
\hline AutoUse11 & .797 & .284 & .089 & -.171 & .107 & .161 & .149 & .017 & -.032 \\
\hline AutoUse14 & .728 & .088 & .117 & .075 & .125 & .224 & .153 & -.035 & .196 \\
\hline Sunk7G & .178 & .815 & .212 & .048 & .116 & .153 & .053 & .044 & .167 \\
\hline Sunk5T & .141 & .812 & .052 & .056 & .075 & .216 & .142 & -.063 & .081 \\
\hline Sunk11E & .284 & .792 & .104 & .109 & .167 & .163 & .172 & -.008 & .084 \\
\hline Sunk8E & .237 & .773 & .116 & .105 & .205 & .250 & .010 & -.042 & .156 \\
\hline Hab5 & .049 & .125 & .856 & .191 & .050 & .155 & .092 & .154 & .113 \\
\hline Hab4 & .158 & .068 & .848 & .081 & .132 & .028 & .040 & .090 & .155 \\
\hline Hab6 & .249 & .203 & .829 & .081 & .031 & .050 & .145 & .107 & .114 \\
\hline Depend2 & -.036 & .068 & .087 & .844 & .094 & .113 & .114 & .135 & .038 \\
\hline Depend1 & .022 & .138 & .026 & .810 & .054 & .061 & .154 & .110 & .183 \\
\hline Depend3 & .077 & .010 & .215 & .767 & .157 & .145 & .075 & .109 & .076 \\
\hline Depend6 & .093 & .180 & .116 & .174 & .858 & .082 & .075 & .065 & .099 \\
\hline Depend7 & .125 & .101 & .147 & .178 & .849 & .022 & .205 & -.052 & .076 \\
\hline Depend9 & .218 & .212 & -.056 & -.037 & .738 & .124 & .299 & -.005 & .067 \\
\hline Rewar3 & .218 & .197 & .195 & .061 & .031 & .819 & .084 & .060 & .026 \\
\hline Rewar1 & .071 & .222 & .080 & .083 & .131 & .768 & .016 & .058 & .142 \\
\hline Rewar4 & .115 & .245 & -.062 & .176 & .036 & .723 & .058 & .036 & .195 \\
\hline Depend11 & .130 & .216 & .071 & .136 & .124 & .040 & .812 & .028 & .091 \\
\hline Depend12 & .067 & .168 & .206 & .236 & .122 & .094 & .756 & .157 & .039 \\
\hline Depend10 & .200 & -.059 & .020 & .037 & .302 & .025 & .727 & -.030 & .133 \\
\hline Facil5 & .078 & .015 & .046 & .103 & -.026 & .078 & .053 & .829 & .211 \\
\hline Facil6 & .037 & -.139 & .142 & .118 & .031 & .108 & .030 & .822 & .050 \\
\hline Facil8 & -.004 & .160 & .342 & .401 & -.006 & -.162 & .061 & .574 & -.111 \\
\hline Urgen4 & -.012 & .111 & .197 & .113 & .050 & .089 & .107 & .133 & .826 \\
\hline Urgen5 & .162 & .204 & .155 & .080 & .171 & .227 & .120 & .026 & .755 \\
\hline Urgen1 & .289 & .300 & .045 & .258 & .076 & .171 & .079 & .226 & .478 \\
\hline
\end{tabular}

Table 2. Factor Analysis

\section{RESULTS}

To assess the measurement model of the study's variables of interest-Automatic IS Use, Perceptions of Sunk Costs, Habit, Reward Responsiveness, Technology-enabled Cuing Mechanisms, Technologyenabled Reward Mechanisms, and Facilitating Conditions - confirmatory factor analysis was performed. All observed indicators were specified to load on their respective latent construct and no observed indicator was allowed to cross-load. To comprehensively gauge model fit we used, in addition to the chisquare test of fit, several fit indices to examine absolute fit, incremental fit, and parsimonious fit. Results indicate that the model fit the data well. The chi-square test was significant $(\chi 2=632.06, \mathrm{df}=369 \mathrm{p}<.01)$, 
however, this was anticipated as our sample consisted of 177 cases and the chi-square test is sensitive to sample sizes (Marsh, Balla, \& McDonald, 1988; Iacobucci, 2010). All other indices examined demonstrated good fit (RMSEA $=.06$, CFI $=.91$, TLI $=.90)$. All observed measures in the analysis demonstrated good construct reliability with estimates that ranged from .72 to .92 thus exceeding the .70 minimum as recommended by Nunnally (1978). Assessment of convergent validity showed that all items loaded significantly on their respective factors with the average variance extracted (AVE) for each latent construct exceeding .50 (Fornell and Larcker, 1981) except for the AVE of the newly developed construct Facilitating Conditions (Facil) which was just under the .50 rule of thumb. Additionally, the average variance extracted for each latent construct must exceed the respective squared correlation between factors to provide stringent evidence of discriminant validity (Fornell and Larcker, 1981). Table 3 below provides this summary.

\begin{tabular}{|c|c|c|c|c|c|c|c|c|c|c|c|}
\hline Variable CR & AVE & 1 & 2 & 3 & 4 & 5 & 6 & 7 & 8 & 9 & \\
\hline AutoUse .89 & .63 & .79 & & & & & & & & & \\
\hline Sunk & .92 & .73 & .54 & .85 & & & & & & & \\
\hline Habit & .90 & .74 & .37 & .42 & .86 & & & & & & \\
\hline BAS_RR .83 & .63 & .10 & .29 & .37 & .79 & & & & & & \\
\hline BAS_DR .87 & .69 & .36 & .44 & .30 & .35 & .83 & & & & & \\
\hline BAS_Fun & .79 & .56 & .39 & .42 & .39 & .43 & .54 & .74 & & & \\
\hline Urgen & .76 & .52 & .40 & .57 & .48 & .42 & .43 & .44 & .72 & & \\
\hline Rewar & .81 & .58 & .44 & .60 & .35 & .33 & .31 & .33 & .57 & .76 & \\
\hline Facil & .73 & .48 & .15 & .08 & .43 & .48 & .09 & .26 & .36 & .21 & .69 \\
\hline
\end{tabular}

Model $(\chi 2 / \mathrm{df}=632.06 / 369)$ RMSEA $=.06, \mathrm{CFI}=.91, \mathrm{TLI}=.90$

Notes: The square root of the AVE is shown in bold on the diagonal of the matrix. The correlation is on the lower triangle. $\mathrm{CR}=$ Construct Reliability, AVE = Average Variance Extracted

\section{Table 3. Results}

Following the assessment of the measurement model the structural model was tested. As our proposed model contained a second order factor (Reward Responsiveness) and mediation (Perceptions of Sunk Costs), Structural Equation Modeling (SEM) using IBM AMOS was used to test the research model hypotheses. Results indicate the model fits the data well with $\chi 2 / \mathrm{df}=899 / 538$. The significant value of chi squared was not surprising as mentioned previously. Other fit indices indicate good fit with RMSEA = .06 with a confidence interval from .05 to $.07, \mathrm{CFI}=.90$ and TLI $=.90 . \mathrm{H} 1(.46, \mathrm{p}<.001), \mathrm{H} 2 \mathrm{a}(.20$, $\mathrm{p}=.02), \mathrm{H} 3 \mathrm{a}(.29, \mathrm{p}=.01), \mathrm{H} 4 \mathrm{a}(.23, \mathrm{p}=.04), \mathrm{H} 5 \mathrm{a}(.32, \mathrm{p}<.001), \mathrm{H} 6 \mathrm{a}(-.27, \mathrm{p}=.01$, and were all supported. The standardized path coefficients and the R2 values for the hypothesized model are shown in figure 3 . 


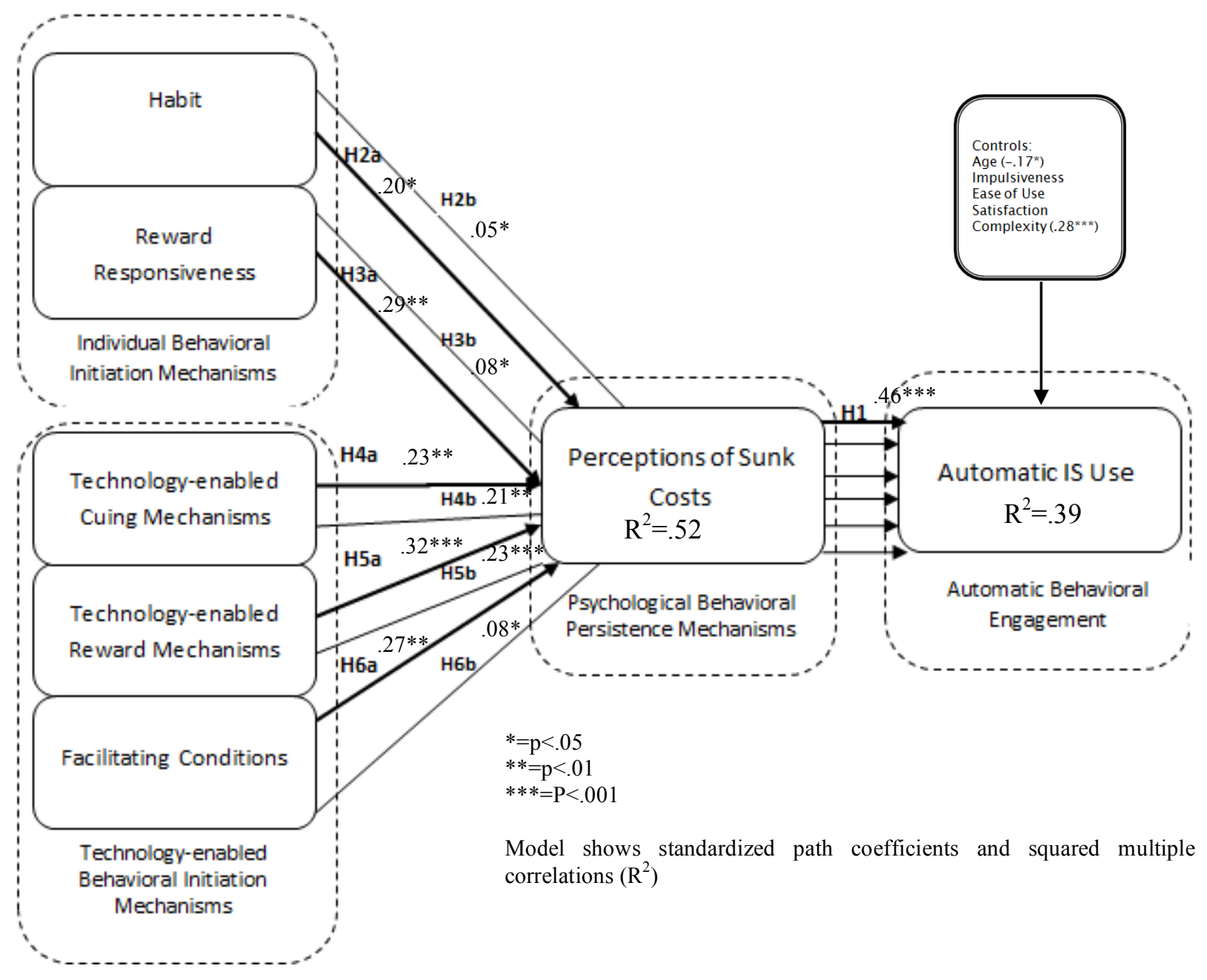

Figure 3. Results

Mediation testing followed Baron and Kenny's (1986) approach which included boot-strapping to $2000 \mathrm{sub}$ samples to assess the significance of the mediation (Iocabucci, 2010). This was done to determine full or partial mediation for each hypothesized path. Full mediation was supported for $\mathrm{H} 3 \mathrm{~b}$ (standardized indirect effect $=.08, \mathrm{p}=.03$ ), $\mathrm{H} 4 \mathrm{~b}$ (standardized indirect effect $=.21, \mathrm{p}=.01$ ), and $\mathrm{H} 5 \mathrm{~b}$ (standardized indirect effect $=.23, \mathrm{p}<.001$ ). Partial mediation was supported for $\mathrm{H} 2 \mathrm{~b}$ (standardized indirect effect $=.05, \mathrm{p}=.05$ ) and $\mathrm{H6b}$ (standardized indirect effect=-.08, $\mathrm{p}=.05$ ). Next, mediation was tested on the nested model by using a chi-square difference test of the competing models. The chi-square value for the competing model in which Perceptions of Sunk Costs do not moderate the effects of the exogenous variables was $\chi 2 / \mathrm{df}=999.4 / 539$. Thus the $\Delta$ $\chi^{2}$ with 1 degree of freedom difference has a significant value of 100.4. As the minimum significant value for this $\Delta \chi^{2}$ with 1 degree of freedom would be 3.84 (which is much lower than 100) it thus provides further evidence of mediation.

DISCUSSION

This study has three key limitations. First, the sample size while sufficient to test the model is relatively small thus limiting our ability to generalize the findings from the study. Second, the study did not focus on a specific voluntary-use technology and instead asked respondents to 
identify one they use most often. This may limit the generalizability of the results since we cannot account for all differences in these technologies. Future work should focus on a specific voluntary-use technology. Third, the cross-sectional nature of the study limits our ability to fully understand the phenomena of interest. Future work should focus on a more longitudinal research design to more comprehensively understand automatic IS use.

\begin{tabular}{|c|c|c|}
\hline Hypothesis & Not Supported & Supported \\
\hline $\begin{array}{l}\text { H1 - An individual's perceptions of sunk costs } \\
\text { will be positively associated with automatic IS } \\
\text { use }\end{array}$ & & $\mathrm{X}$ \\
\hline $\begin{array}{l}\text { H2a - Habit will be positively associated with } \\
\text { the perceptions of sunk costs }\end{array}$ & & $\mathrm{X}$ \\
\hline $\begin{array}{l}\mathrm{H} 2 \mathrm{~b} \text { - The effect of habit on automatic IS use } \\
\text { will be mediated by perceptions of sunk costs }\end{array}$ & & $\mathrm{X}$ \\
\hline $\begin{array}{l}\mathrm{H} 3 \mathrm{a}-\text { Reward responsiveness will be positively } \\
\text { associated with perceptions of sunk costs }\end{array}$ & & $X$ \\
\hline $\begin{array}{l}\mathrm{H} 3 \mathrm{~b}-\text { The effect of reward responsiveness on } \\
\text { automatic IS use will be mediated by perceptions } \\
\text { of sunk costs. }\end{array}$ & & $\mathrm{X}$ \\
\hline $\begin{array}{l}\mathrm{H} 4 \mathrm{a}-\mathrm{Technology-enabled} \mathrm{cuing} \mathrm{mechanisms} \\
\text { will be positively associated with perceptions of } \\
\text { sunk costs. }\end{array}$ & & $\mathrm{X}$ \\
\hline $\begin{array}{l}\mathrm{H} 4 \mathrm{~b}-\text { The effect of technology-enabled cuing } \\
\text { mechanisms on automatic IS use will be } \\
\text { mediated by perceptions of sunk costs. }\end{array}$ & & $\mathrm{X}$ \\
\hline $\begin{array}{l}\text { H5a - Technology-enabled reward mechanisms } \\
\text { will be positively associated with perceptions of } \\
\text { sunk costs. }\end{array}$ & & $X$ \\
\hline $\begin{array}{l}\mathrm{H} 5 \mathrm{~b}-\text { The effect of technology-enabled reward } \\
\text { mechanisms on automatic IS use will be } \\
\text { mediated by perceptions of sunk costs. }\end{array}$ & & $\mathrm{X}$ \\
\hline $\begin{array}{l}\text { H6a - Facilitating conditions will be positively } \\
\text { associated with perceptions of sunk costs }\end{array}$ & $\mathrm{X}$ & \\
\hline $\begin{array}{l}\text { H6b - The effect of facilitating conditions on } \\
\text { automatic IS use will be mediated by perceptions } \\
\text { of sunk costs }\end{array}$ & & $X$ \\
\hline
\end{tabular}

Table 4. Hypothesis Summary

Table 4 provides a summary of the results. The results of the analysis provide support for all the stated hypotheses except for H6a. H1 showed that perceptions of sunk costs were positively associated with automatic IS use. H2a showed that habit was positively associated with perceptions of sunk costs. H2b showed that the effect of habit on automatic IS use was only partially mediated by perceptions of sunk costs. H3a showed that reward responsiveness was positively associated with perceptions of sunk costs. $\mathrm{H} 3 \mathrm{~b}$ showed that perceptions of sunk costs fully mediated the relationship of habit on automatic IS use. $\mathrm{H} 4 \mathrm{a}$ showed that the technology-enabled cuing mechanisms were positively associated with perceptions of sunk costs. $\mathrm{H} 4 \mathrm{~b}$ showed that the effect of technology-enabled cuing mechanisms on automatic IS use 
was fully mediated by perceptions of sunk costs. H5a showed that the technology-enabled reward mechanisms were positively associated with perceptions of sunk costs. H5b showed that perceptions of sunk costs fully mediated the effect of technology-enabled reward mechanisms on automatic IS use. H6a was not supported as this hypothesis assumed that facilitating conditions would be positively associated with perceptions of sunk costs. The findings indicate that this relationship is significant, however in the opposite direction as posited. H6b showed that the effect of facilitating conditions on automatic IS use is partially mediated.

In further examination of what could drive the significant negative association of H6a it is possible that the new conceptualization of facilitating conditions captures notions of the universal accessibility, multiplatform availability and cross system compatibilities of a voluntary-use information system. These could be considered at the extreme end of a facilitating conditions spectrum. Considering this as a highly available and ubiquitous technology, it should not be surprising that the value associated with past use (i.e.., perceptions of sunk costs) would be lower, as facilitating conditions imply that individuals perceive significantly lower amounts of effort, time or money have been exerted. Any amount of actual physical, mental, temporal or monetary exertion seems to be negated by their perception that they can ubiquitously interact with their voluntary-use information system. This unexpected, finding has interesting future implications for research.

In closing, the findings of this research support the general hypothesis that internal behavioral initiation mechanisms - such as an individual's habits and reward responsiveness, and external behavioral initiation mechanisms - such as technology features which act as cuing and reward mechanisms serve to prime and initiate technology interactions which subsequently lead to behavioral persistence mechanisms which manifest as an increased value associated with past use (i.e., perceptions of sunk costs). Additionally support is found for the hypothesis that these behavioral persistence mechanisms - such as perceptions of sunk costs, will begin to drive non-intentional context-response associations in the form of automatic IS use. The specific findings of this research provide initial support for several possible contributions to research and theory. First, IS habit is distinct from automatic IS use and the implications of this distinction may serve to guide future studies of voluntary-use information systems. Second, perceptions of sunk costs exhibit properties of an effective psychological construct; a construct which has yet to be fully explored in IS research. Third, individual affective dispositions - often overlooked in current IS research-such as reward responsiveness, are useful in predicting technology interaction and should be considered in future studies. Finally, the importance of the "artifact" in IS research is restated as design features have been shown here to have powerful behavioral implications.

\section{REFERENCES}

1. Ajzen, I. \& Fishbein, M. (2005). The Influence of Attitudes on Behavior. In D. Albarracin, B.T. Johnon, \& M. P. Zanna (Eds.), The Handbook of Attitudes. Mahwah, NJ: Erlbaum, 173-221.

2. Al-Natour, S. and Benbasat, I. (2009) The adoption and use of IT artifacts: A new interaction-centric model for the study of user-artifact relationships, Journal of the Association for Information Systems, $10,9,661-685$.

3. Arkes, H. R. and Blumer, C. (1985) The Psychology of Sunk Cost, Organizational Behavior and Human Decision Processes, 35, 124-140.

4. Bagozzi, R. P., \& Warshaw, P. R. (1990). Trying to consume. Journal of consumer research, 127140.

5. Baron, R. M., \& Kenny, D. A. (1986). The moderator-mediator variable distinction in social psychological research: Conceptual, strategic, and statistical considerations. Journal of personality and social psychology, 51(6), 1173. 
6. Bhattacherjee, A. (2001). Understanding information systems continuance: an expectationconfirmation model. MIS quarterly, 351-370.

7. Clements, J. A., and Bush, A. A., (2011 b). Perceptions of Sunk Cost and Habitual IS Use, AMCIS 2011 Proceedings, 84, 1-8.

8. Carver, C. S., \& White, T. L. (1994). Behavioral Inhibition, Behavioral Activation, and Affective Responses to Impending Reward and Punishment: The BIS/BAS Scales, Journal of Personality and Social Psychology, 67, 2, 319-333.

9. Dahlstrand, U. and A. Biel (1997) Pro-Environmental Habits: Propensity Levels in Behavioral Change, Journal of Applied Social Psychology, 27, 7, 588-601.

10. de Guinea, A. O. and Markus, M. L. (2009) Why break the habit of a lifetime? Rethinking the roles of intention, habit, and emotion in continuing information technology use, MIS Quarterly, 33, 3, 433444.

11. Davis, F. D., Bagozzi, R. P., Warshaw, P. R. (1989) User acceptance of computer technology: A comparison of two theoretical models, Management Science, 35, 8, 982-1003.

12. Fornell, C., \& Larcker, D. F., (1981), Evaluating Structural Equation Models with Unobservable Variables and Measurment Error, Journal of Marketing Research, 18, 1, 39-50.

13. Gray, J. A. (1990). Brain Systems that Mediate both Emotion and Cognition, Cognition and Emotion, 4, 269-288.

14. Hevner, A. R., March, S. T., Park, J., \& Ram, S. (2004) Design science in information systems research, MIS Quarterly, 28, 1, 75-105.

15. Hull, C. L. (1943) Principles of behavior: An introduction to behavior theory. New York: AppletonCentury-Crofts.

16. Iacobucci, D., (2010), Structural Equations Modeleing: Fit Indices, Sample Size, and Advanced Topics, Journal of Consumer Psychology, 20, 90-98.

17. Ip, R. K., \& Ho, A. K. (2015). A Study of the Uses of Instant Messaging in the Government Offices. In HCI in Business (pp. 96-105). Springer International Publishing.

18. James, W. J., (1890). The Principles of Psychology. New York: Dover.

19. Kaiser, H. F. (1970). A second generation little jiffy. Psychometrika, 35(4), 401-415.

20. Limayem, M., \& Hirt, S. G. (2003). Force of habit and information systems usage: Theory and initial validation. Journal of the Association for Information Systems, 4(1), 3.

21. Limayem, M., Hirt, S. G. et al. (2007) How habit limits the predictive power of intention: The case of information systems continuance, MIS Quarterly, 31, 4, 705-737.

22. Lankton, N. K., Wilson, E. V., \& Mao, E. (2010). Antecedents and Determinants of Information Technology Habit, Information \& Management, 47, 300-307.

23. MacMillan, D. (2011) Gamification: A Growing business to Invigorate Stale Websites, Bloomberg Businessweek, Retrieved, 1/20/2011 from www.businessweek.com

24. Marsh, H. W., Balla, J. R., \& McDonald, R. P. (1988), Goodness of Fit in Confirmatory Factor Analysis: The Effect of Sample Size., Psychological Bulletin, 103, 391-410.

25. Moore, G. C., \& Benbasat, I. (1991). Development of an instrument to measure the perceptions of adopting an information technology innovation. Information systems research, 2(3), 192-222. 
26. Neal, D. T., Wood, W., \& Quinn, J. M. (2006). Habits: A repeat performance, Current Directions in Psychological Science, 15, 198-202.

27. Nunnally, J. (1978). Psychometric methods.

28. Ouellette, J. A. and W. Wood (1998) Habit and intention in everyday life: The multiple processes by which past behavior predicts future behavior, Psychological Bulletin, 124, 1, 54-74.

29. Oulasvirta, A., Rattenbury, T., Ma, L. \& Raita, E. (2012). Habits Make Smartphone Use More Pervasive, Journal of Personal and Ubiquitous Computing, 16, 1, 105-114.

30. Simon, H. A. (1950). Administrative Behavior, A Study of Decision-Making Processes in Administrative Organization. Macmillan, New York.

31. Staw, B. M., and Hoang, M. (1995) Sunk costs in the NBA: Why Draft Order Affects Playing Time and Survival in Professional Basketball, Administrative Science Quarterly, 40, 3, 474-494

32. Tiwana, A., \& Bush, A. (2005). Continuance in expertise-sharing networks: A social perspective. Engineering Management, IEEE Transactions on, 52(1), 85-101.

33. Thompson, R. L., Higgins, C. A., and Howell, J. M. (1991) Personal Computing: Toward a Conceptual Model of Utilization, MIS Quarterly, 15, 1, 124-143.

34. Triandis, H. C. (1977). Interpersonal Behavior, Monterey, CA: Brooks/Cole Publishing Company.

35. Venkatesh, V. (2000). Determinants of perceived ease of use: Integrating control, intrinsic motivation, and emotion into the technology acceptance model. Information systems research, 11(4), 342-365.

36. Venkatesh, V., \& Davis, F. D. (1996). A model of the antecedents of perceived ease of use: Development and test*. Decision sciences, 27(3), 451-481.

37. Venkatesh, V., Morris, M.G., Davis, F.D., and Davis, G.B. (2003) User acceptance of information technology: Toward a unified view, MIS Quarterly, 27, 3, 425-478.

38. Verplanken, B. (2006). Beyond Frequency: Habit as Mental Construct, British Journal of Social Psychology, 45, 639-656.

39. Verplanken, B. \& Aarts, H. (1999). Habit, Attitude, and Planned Behavior: Is Habit an Empty Construct or an Interesting Case of Goal-Directed Automaticity? European Review of Social Psychology, 10, 101-134.

40. Verplanken, B., \& Orbell, S. (2003). Reflections on Past Behavior: A Self-Report Index of Habit Strength, Journal of Applied Social Psychology, 33, 1313-1330.

41. Whiteside, S. P., \& Lynam, D. R. (2001). The five factor model and impulsivity: Using a structural model of personality to understand impulsivity. Personality and individual differences, 30(4), 669689.

42. Wood, W., \& Neal, D. T., (2007). A New Look at habits and the Habit-Goal Interface, Psychological Review, 114, 4, 843-863.

43. Wood, W., Quinn, J. M., \& Kashy, D. A. (2002). Habits in Everyday Life: Thought, Emotion, and Action, Journal of Personality and Social Psychology, 83, 1281-1297. 


\begin{tabular}{|c|c|}
\hline \multirow{8}{*}{ Automatic IS Use } & I find myself using this technology at inopportune times \\
\hline & I feel I sometimes automatically start using this technology \\
\hline & $\begin{array}{l}\text { I choose this technology without even being aware of making the } \\
\text { choice }\end{array}$ \\
\hline & I unconsciously start using this technology \\
\hline & I often find myself using this technology \\
\hline & $\begin{array}{l}\text { Using this technology is something I do without even being aware } \\
\text { of it }\end{array}$ \\
\hline & $\begin{array}{l}\text { I find myself checking in with this technology without explicitly } \\
\text { planning to do so }\end{array}$ \\
\hline & I sometimes feel compelled to use this technology \\
\hline \multirow{6}{*}{ Perceptions of Sunk Costs } & I have put a lot of time into getting the hang of this technology \\
\hline & I feel I have invested considerable time using this technology \\
\hline & I have put a lot into my use of this technology \\
\hline & I have invested a great deal of effort into using this technology \\
\hline & I feel I have spent a great deal of energy using this technology \\
\hline & I feel I have put considerable effort into using this technology \\
\hline \multirow{5}{*}{ Habit } & The use of this technology has become a habit for me \\
\hline & I don't even think twice before using this technology \\
\hline & Using this technology has become natural to me \\
\hline & Using this technology has become automatic to me \\
\hline & $\begin{array}{l}\text { When faced with a particular task, using this technology is an } \\
\text { obvious choice for me }\end{array}$ \\
\hline
\end{tabular}




\begin{tabular}{|c|c|}
\hline \multirow{9}{*}{ Reward Responsiveness } & When I get something I want, I feel excited and energized \\
\hline & When I'm doing well at something, I love to keep at it \\
\hline & When good things happen to me, it affects me strongly \\
\hline & When I want something, I usually go all-out to get it \\
\hline & I go out of my way to get things I want \\
\hline & When I go after something I use a "no holds barred" approach \\
\hline & I will often do things for no other reason than that they might be fun \\
\hline & I crave excitement and new sensations \\
\hline & I'm always willing to try something new if I think it will be fun \\
\hline \multirow{4}{*}{$\begin{array}{c}\text { Technology-Enabled Cuing } \\
\text { Mechanisms }\end{array}$} & This technology has a way of prompting me to use it \\
\hline & I often feel a sense of urgency to use this technology \\
\hline & This technology lets me know when there is information for me \\
\hline & This technology lets me know when there is something for me to do \\
\hline \multirow{4}{*}{$\begin{array}{c}\text { Technology-Enabled Reward } \\
\text { Mechanisms }\end{array}$} & This technology has a way of rewarding me for using it \\
\hline & I feel a sense of reward when I use this technology \\
\hline & This technology provides me with feedback \\
\hline & I feel I get something out of using this technology \\
\hline \multirow{6}{*}{ Facilitating Conditions } & I have a good understanding of how to use this technology \\
\hline & I have easy access to this technology \\
\hline & I have inexpensive access to this technology \\
\hline & This technology is available to me on multiple technology devices \\
\hline & This technology is compatible with multiple system technologies \\
\hline & I am able to access this technology from multiple locations \\
\hline
\end{tabular}

